\title{
ADIVINACIÓN Y PRESAGIOS EN EL BAJO IMPERIO ROMANO SEGÚN AMIANO MARCELINO
}

\author{
Narciso SANTOS YANGUAS \\ Universidad de Oviedo
}

\begin{abstract}
RESUMEN: En el siglo IV d.C. los romanos encontraron en sus convicciones religiosas, así como en su propia cultura, motivos suficientes para creer en las prácticas adivinatorias. Uno de los rasgos de la mentalidad pagana consistía en ver en los hechos naturales una constante intervención divina y una consecuencia de los mensajes enviados a los hombres para estimular la ejecución de sus proyectos. Adivinación y presagios no sólo no experimentan una decadencia durante dicha centuria sino que Amiano Marcelino parece buscar en sus Res Gestae justificación a tales prácticas.
\end{abstract}

PALABRAS CLAVE: adivinación, presagios, Bajo Imperio romano, mentalidad pagana, intervención divina.

ABSTRACT: In the 4th century A.D. the Romans found in their own religious convictions and in their own culture reasons to believe in the practices of the diviners. One of the main features in the pagan mentality is to be found in the natural events as the outcome of divine intervention and a consequence of the messages sent to men to stimulate the execution of projects. Divination and presages will not suffer a process of decay during the said century and Ammianus Marcellinus seems to be trying to find in his Res Gestae justification of the practices mentioned.

KEYWORDS: divination, presages, Later Roman Empire, pagan mentality, divine intervention.

\section{INTRODUCCIÓN}

Las creencias en los presagios y prodigios no desaparecerían en ninguna fase de la historia romana de los planteamientos ideológicos inherentes al paganismo, aun cuando sabemos que atravesarían por momentos y niveles muy diferentes, en especial en todo lo relativo a sus conexiones con la mántica ${ }^{1}$.

No es de extrañar, por tanto, que los ciudadanos romanos del siglo IV hallaran en su ideología religiosa, al igual que en el ámbito de su propia cultura, motivación suficiente para depositar su confianza en los adivinos.

${ }^{1}$ Remitimos, por ejemplo, a análisis ya tradicionales como los de BAYET, J. (1949). "La croyance romaine aux présages déterminants, aspect littérarire et chronologie". En Mélanges Bidez-Cumont. Bruselas: pp. 14ss., y BLOCH, R. (1956). "Les prodigies et la divination dans l'Italie ancienne". Diogène 16, pp. 62ss. 
Durante esa centuria Julio Obsequente recopilaría el conjunto de prodigios que Tito Livio había ido desperdigando en sus escritos sobre la historia de Roma² .

La cantidad tan amplia de los mismos, unido a la extensión de sus relatos y al dominio del lenguaje artístico de su composición y exposición, documentan la importancia atribuida a este aspecto de la religión romana.

El análisis de los pasajes en que dicho autor recoge tales prodigios manifestando una aceptación y profesión de fe religiosa permite identificarlo con un escritor históricamente fiel a la más rancia tradición romana y, además, que se hallaba convencido plenamente de ello ${ }^{3}$.

Sin embargo sabemos que Amiano Marcelino, el último gran historiador del mundo romano a pesar de su origen griego ${ }^{4}$, conocería a la perfección, bien directamente bien por medio de abreviadores, el conjunto de la obra histórica de Tito Livio ${ }^{5}$, de lo que daría muestras evidentes en innumerables relatos de sus Res Gestae.

\section{LOS MALOS PRESAGIOS}

La importancia y significado cada vez mayores que adquieren los presagios (tanto de signo positivo como contrario), así como el papel que desempeñaban como anticipadores de hechos fatales, llevarían al antioqueno a utilizarlos como ejemplo en muchos de los pasajes de su obra:

- En primer lugar cabe destacar el nacimiento en Dafne (barrio de Antioquía) de un monstruo repugnante, un niño con barbas, dos bocas, dentadura doble, cuatro ojos.... (Amm.Marc. 19.12.19) ${ }^{6}$; esta criatura recién llegada al mundo, tan contrahecha, constituía sin duda un presagio de lo que iba a convertirse después en la ruina del poder romano.

${ }^{2}$ Ver, entre otros autores que han tratado este tema, los estudios de JiménEZ, J. (1961). "Importancia de los prodigios en Tito Livio". Helmantica 22, pp. 27ss., e Id. (1961). "Clasificación de los prodigios titolivianos". Helmantica 22, pp. 441ss.

3 Para más detalles remitimos a KAJANTO, E. (1957). God and Fate in Livy. Kustantama. Cf. DAvies, J. P. (2004). Rome's Religious History: Livy, Tacitus and Ammianus on their Gods, Londres: pp.161ss.

${ }^{4}$ Él mismo se califica (31.16.9) como miles quondam et graecus. Cf. BEST,E. E. (1966). "The Literate Roman Soldier". CJ 72, pp. 122ss.

${ }^{5}$ Sobre estas cuestiones remitimos, entre otros, a LEOUTRE, G. (1962). Tite Live, instrument de la propagande païenne à la fin du IVe siècle et au début du Ve siècle. París.

${ }^{6}$ Libanio realiza un gran elogio de esta barriada en su Antiockos. Cf. FESTUGIÈRE, R. P. Antioche païenne et chrétienne, París 1959, pp.30-32. 
- "Nacimientos de esta naturaleza, prosigue el historiador, tienen lugar con bastante frecuencia y anuncian la dirección que van a tomar los distintos asuntos; pero, al no ser objeto de purificaciones oficiales, como lo eran en tiempos de nuestros antepasados, apenas se habla de ellos y pasan desapercibidos" (Amm.Marc. 19.12.20);

- Junto a ello sobresale la consulta continuada de los libros sibilinos en la capital del Imperio, que se manifestaron desfavorables en su totalidad al emperador Juliano: "en aquellos días se le anunció a través de una carta que en Roma los libros de la Sibila habían sido consultados acerca de esta guerra (contra los persas) como había ordenado y que habían dado como respuesta definitiva que el emperador no podría abandonar sus fronteras durante aquel año" (Amm.Marc. 23.1.7);

- Igualmente la interpretación del examen de las entreañas de las víctimas a favor del emperador Joviano: "mientras se cumplían estas medidas en ambos bandos, fueron sacrificadas víctimas en favor de Joviano y, una vez examinadas sus entrañas, se anunció que éste lo perdería todo en el caso de permanecer dentro del muro defensivo de su campamento (como pensaba hacer), pero que quedaría vencedor si se ausentaba de él" (Amm.Marc. 25.6.1);

- También la aparición, en el año 363, de nuevos signos de la cólera del numen celestial, que los versados en magia y adivinación interpretaron como luctuosas y siniestras (Amm.Marc. 25.10.1: ....quorum eventus fore luctificos gnari rerum prodigialium praecinentes), como por ejemplo el hecho de que la estatua del césar Maximiano, ubicada en el vestíbulo de la residencia imperial, de repente perdió la esfera de bronce que sujetaba en sus manos y que figuraba el mundo, lo que provocó de inmediato un desencadenamiento de fenómenos astrológicos en el firmamento (Amm.Marc. 25.10.2-3)

- Sin duda los más evidentes (y al mismo tiempo nefastos) presagios se relacionarían con la muerte del emperador Valente y la invasión del Imperio

${ }^{7}$ Ver igualmente SHA, Tacitus 16.6; Lact., mort.persec. 44 y Zos. 2.16. Cf. BROK,M. F. A. (1959). De perzische expeditie van Keizer Julianus volgens Ammianus Marcellinus, Groninga: p.32.

${ }^{8}$ Brok, M. F. A. De perzische expeditie van Keizer Julianus volgens Ammianus Marcellinus: pp.240-242. Cf. SANTOS, N. (2007). "Numen y deus en la concepción religiosa de Amiano Marcelino". Estudios humanísticos 6, 9ss. 
por parte de los godos (Amm.Marc. 31.1.2-4) ${ }^{9}$.

En este sentido en incontables oportunidades nos va a presentar el historiador pruebas evidentes de lo acertado de su opinión, como, por ejemplo, en el hecho de que la región de Toscana annonaria sería testigo de un prodigio que haría equivocarse a los más hábiles en la ciencia adivinatoria.

Los hechos sucederían de la siguiente manera: en el centro urbano de Pistoia, ante una gran concentración de población, un asno ascendió hasta el tribunal y se puso a rebuznar durante un prolongado espacio de tiempo, produciendo con ello una gran estupefacción entre quienes lo observaban (Amm.Marc. 27.3.1).

Cuantos se esforzaban en interpretar dicha señal quedaron perplejos ante la predicción futura, aunque los acontecimientos posteriores se encargarían de dar una explicación fidedigna al respecto: un antiguo panadero llegó a obtener, como premio a una acusación de delación, el cargo de corrector de dicha provincia, manifestándose después en el desempeño de sus funciones con una insolencia no acorde con dichas funciones.

En un episodio que tendría lugar algún tiempo después aparece reseñada una credulidad de similares características: en el año 368 había anidado en Roma un régimen completo de terror, cuyo principal instigador no era otro que el panonio Máximo, en aquel entonces al frente de la prefectura urbana (Amm.Marc. 28.1.1ss.) $)^{10}$.

Dicha situación tan calamitosa se había originado por un motivo aparentemente trivial, consistente en la utilización de las artes mágicas con el objetivo de seducir a una mujer; sin embargo, a consecuencia del proceso incoado por este hecho, vería la luz todo un conjunto de adulterios, así como otra serie de ofensas que involucraron a personas de origen y situación social alta, entre quienes se encontraban los integrantes del grupo familiar de los Anicios.

Como resultado de ello un número significativo de las persecuciones judiciales a que daría pié finalizarían con la muerte y el destierro, habiéndose llevado la aplicación de estas medidas represivas hasta sus últimas consecuencias, de manera que un joven de origen familiar noble, Loliano de nombre, sería ejecutado

9 Austin, N.J.E. (1972). "Ammianus'Account of the Adrianople Campaign: Some Strategic Observations". AClass 15, 77ss.

${ }^{10}$ Syme, R. (1968). Ammianus and the Historia Augusta. Oxford: pp.31-32. 
simplemente por la acusación de que se había atrevido a copiar un libro de brujería $^{11}$.

Sería igualmente en aquellos momentos cuando se vieron crecer las escobillas utilizadas para la limpieza de la sala de sesiones del senado, lo que fue interpretado por algunos como presagio de la llegada a los honores más elevados de personas de muy bajo nivel y consideración social (Amm.Marc. 28.1.42).

No obstante, uno de los ejemplos más representativos de este tipo de presagios que se recogen en las Res Gestae amianeas lo constituyen los signos precursores de la muerte de los diferentes emperadores.

Con anterioridad, en el marco de la historiografía latina, encontramos ya una larga enumeración de prodigios en las biografías de Suetonio, cuya manifestación más evidente se hacía patente siempre en los momentos inmediatos a la desaparición de los Césares ${ }^{12}$.

Igualmente, aunque se vinculen con hechos de naturaleza algo distinta, los pasajes que Virgilio y Lucano habían dedicado, por ejemplo, a anunciar premonitoriamente las guerras civiles se mantenían vigentes en el recuerdo de todos los ciudadanos romanos durante el siglo $\mathrm{IV}^{13}$.

Además, junto a hechos de esta índole el historiador antioqueno llega a describir, incluso de forma placentera, este tipo de sucesos, sirviéndole en numerosas ocasiones como pretexto para elaborar narraciones brillantes desde el punto de vista estrictamente literario ${ }^{14}$.

La mejor composición de todas ellas sería sin duda la que corresponde al inicio del último libro de las Historias amianeas, en la que se van a ir acumulando los presagios más nefastos y contrarios (la invasión de los godos, el fracaso de los ejércitos romanos ante ellos $\mathrm{y}$, finalmente, la muerte trágica del emperador Valente):

${ }^{11}$ Este hecho debe enmarcarse entre un conjunto de tribulaciones quae decolorabant speciem urbis aeternae (Amm.Marc. 28.1.36).

${ }^{12}$ Ver, por ejemplo, Caes. 81; Aug. 117; Tib. 74 y Calig. 57.

${ }^{13}$ Verg., Georg. 1.464-488 y Luc., Phars. 1.522ss.

14 Por ejemplo con anterioridad a las muertes de Constancio (Amm.Marc. 21.15.2), de Joviano (25.10.1), de Valentiniano (30.5.15) y de Valente (31.1.2-4). Cf. SAMBERGER,Ch. (1969). "Die "Kaiserbiographie" in den Res Gestae des Ammianus Marcellinus". Klio 51, 349ss. 
"La aproximación de estas catástrofes, puntualiza nuestro autor, se hallaba marcada por claras indicaciones de presagios y prodigios.

Además de otras muchas predicciones correctas de arúspices y augures.... los perros hacían eco con los aullidos de los lobos; los pájaros piaban de noche con un tono agudo su lastimera queja; el sol, nublado en el momento de su salida, empañaba las blancuras matinales del alba" (Amm.Marc. 31.1.2).

\section{INTERPRETACIÓN DE LOS PRESAGIOS}

Pero es que, por otra parte, esta credulidad puesta de relieve por nuestro historiador viene acompañada por lo general de un formalismo que parece acoplarse perfectamente a las apariencias de la razón.

Así pues, no es por ceguera por lo que muestra su adhesión a las palabras de los adivinos sino que a éstos hay que considerarlos, desde su óptica, como depositarios de una ciencia cuya antigüedad garantiza su exactitud, siendo en consecuencia un paso eminentemente racional el que conduce al autor a inclinarse ante ella.

De esta manera la interpretación de los presagios se convierte en una especie de ejercicio intelectual, que consiste sobre todo en descubrir el significado de un fenómeno histórico sin dejarse arrastrar por la ambigüedad en la que se halla envuelto en cuantiosas ocasiones ${ }^{15}$.

En ese contexto las equivocaciones interpretativas no pueden equivaler más que al resultado de la ignorancia o complacencia, aspectos que vienen subrayados por el autor de Antioquia en diversos pasajes: por ejemplo, en relación con uno de los sueños de Constancio, asegura que "mostraba con claridad una revolución, a pesar de que se hubiera logrado encontrarle una explicación favorable" (Amm.Marc. 21.14.1).

Junto a ello, como ejemplo de inadecuada interpretación de los acontecimientos, nuestro historiador señala que el 1 de enero del 363, en el marco de la ciudad de Antioquia, en el momento en que Juliano subía las escaleras de un templo, el decano de los sacerdotes cayó fulminado de repente a causa de una muerte repentina.

${ }^{15}$ CAmus, P. M. (1967). Ammien Marcellin, témoin des courants culturels et religieux à la fin du IVe siècle. París: p.212. 
Cuantos se hallaban presentes en el lugar, no se sabe si por ignorancia o más bien buscando agradar con ello al emperador, aplicaron este nefasto presagio al mayor de los dos cónsules, Salustio (Amm.Marc. 23.1.6).

Sin embargo, los acontecimientos ocurridos con posterioridad dejarían bien a las claras que no era al cónsul más anciano sino al personaje de rango más elevado a quien iba dirigida dicha advertencia premonitoria de carácter nefasto.

Por otro lado sabemos que, en el momento de enfrentarse con Constancio II en la que sería la lucha decisiva, la vacilación se apodera de Juliano, quien, preso de los nervios, no deja de escudriñar las entrañas de las víctimas y de observar el vuelo de las aves, a pesar de que dichas actividades no iban a disipar en modo alguno sus temores (Amm.Marc. 22.1.3).

Es más, la posterior predicción favorable emitida por un adivino tomando como base el examen de un hígado de doble tegumento, tampoco le llevaría a abandonar sus incertidumbres, puesto que sospechaba alguna superchería de complacencia hacia su persona, de manera que la predicción en el fondo continuaba sin aclararse $^{16}$.

Como consecuencia de ello en todo lo referente a las interpretaciones que entrañan alguna duda el autor nos remite a la decisión de los especialistas, a los que considera como los únicos intermediarios que poseen las competencias precisas para ello.

En esta misma dirección se enmarca el conflicto que, en dos oportunidades, enfrentaría a los arúspices y filósofos del círculo de Juliano: en el transcurso de la marcha del emperador contra los persas, en el momento de acercarse a la ciudad abandonada de Dura, observó cómo se aproximaba a él un grupo de soldados, quienes le ofrecieron el cuerpo de un enorme león al que acababan de dar muerte con sus dardos (Amm.Marc. 23.5.8ss.).

De este hecho, así como de algunos otros presagios asociados a él (como la muerte de un soldado del séquito de Joviano y de dos caballos, fulminados todos ellos por un rayo), se desprendió la interpretación de un final feliz de la aventura contra los persas, por lo que dio orden de proseguir el viaje $\mathrm{e}^{17}$.

16 EnssLin, W. (1971). Zur Geschichtsschreibung und Weltsanchauung des Ammianus Marcellinus. Aalen: p.85.

${ }^{17}$ Straub, J. (1952). "Das Ctesiphon-Orakel". En Studien zu Historia Augusta. Berna : p.132. 
Aborda el historiador en este momento de su narración una discusión, puesto que el presagio podía ser interpretado de dos maneras diferentes y los acontecimientos posteriores decidirían de forma contraria a lo que lo habían hecho las primeras interpretaciones sobre el mismo.

Una vez consultados los arúspices etruscos (Amm.Marc. 23.5.13: harum rerum interpretes) ${ }^{18}$, adujeron, valiéndose de la ayuda de sus tratados, la explicación correcta, que sería confirmada por los hechos poco tiempo después: el presagio resultaba desfavorable al emperador que se hallaba al frente del asalto, a pesar de que le acompañaba la justicia de la causa (Amm.Marc. 23.5.10) ${ }^{19}$.

Aparece entonces en escena el grupo de filósofos para manifestar su oposición a dicha interpretación (Amm.Marc. 23.5.11), y para ello hacen alusión a un hecho anterior, que según ellos fundamentaba su opinión: en unas circunstancias muy parecidas se había ofrecido a Maximiano un león durante sus enfrentamientos con los persas, resultando vencedor en dicha expedición.

La discusión se reanudaría al día siguiente cuando un soldado, que llevaba sus animales al abrevadero, cayó muerto alcanzado por un rayo ${ }^{20}$.

A continuación los adivinos, basando la interpretación en el examen de sus libros, fueron de la opinión de que se trataba de una nueva advertencia que presagiaba que el comportamiento correcto sería el de renunciar a esta empresa militar contra los persas.

Esta forma de analizar las cosas conduciría a un nuevo enfrentamiento con el grupo de filósofos, quienes se refugian en un análisis exclusivamente físico del fenómeno natural del rayo (Amm.Marc. 23.5.14) ${ }^{21}$, añadiendo a continuación que, en el caso de que se quisiera deducir de ese hecho una predicción para el futuro, era preciso ver en él un signo favorable.

Al llegar a esta altura de su exposición el historiador tomaría partido por el grupo de los adivinos, en cuya ciencia reconoce un valor absoluto.

\subsection{9 .}

${ }^{18}$ Ver igualmente Séneca, Nat.Quaest. 2.31-41; Plin., N.H. 2.137-148 y Cic., de divin. 2.18.42 -

${ }^{19}$ Ver igualmente Cas., Var. 11.1. Sin embargo, a pesar de que el emperador despreciaba los consejos de los arúspices y su ciencia, los consulta la víspera de su muerte (Amm.Marc. 25.2.7).

${ }^{20}$ A partir de esta parte del relato Amiano parece inclinarse de parte de los arúspices.

${ }^{21}$ Meulder, M. (1991). "Julien l'Apostat contre les Parthes: un guerrier impie". Byzantion 61, pp. 458ss. 
En contraposición va a manifestar una clara desconfianza con respecto al séquito de filósofos que se amontonaban en torno a Juliano (no así contra Máximo de Éfeso y Prisco, a quienes nos muestra conversando animadamente con el emperador en torno a la inmortalidad del alma, sino contra sus discípulos) ${ }^{22}$.

La oposición tajante y sistemática que muestra dicho emperador (a quien no debemos olvidar que Amiano consideraba el prototipo de buen gobernante en el Bajo Imperio) con respecto a las palabras de los arúspices suscita en nuestro escritor no tanto la condena por la explicación física del fenómeno en sí del rayo cuanto por la negativa a que se considere como un mensaje divino.

Indicaciones del mismo cariz volverá a realizar con posterioridad con respecto a otra circunstancia similar: la noche previa al enfrentamiento bélico en el que Juliano iba a encontrar la muerte, el emperador observaría en el cielo una estela luminosa que atravesó el firmamento y se estremecería pensando que se trataba de la estrella de Marte que se manifestaba a través de este aspecto siniestro (Amm.Marc. 25.2.4-7).

De acuerdo con el antioqueno este vulgar meteoro debería ser interpretado como alguna señal del cielo, a la que el emperador, sustituyendo a los filósofos, considera que no había que tomar en consideración en sí misma, a pesar de las prevenciones que una vez más los arúspices indicaron ${ }^{23}$.

\section{CONCLUSIONES}

A pesar de la legislación imperial que durante el siglo IV se emitiría contra todas estas prácticas ${ }^{24}$, resulta evidente que la creencia en el valor indicativo y determinante de los presagios nunca dejaría de afianzarse en el mundo psicológico de los romanos en dicha época.

Sin embargo, este tipo de creencias se mostrarían compatibles en todo momento con un racionalismo pragmático; en ese contexto el hecho de que algunos prodigios

\footnotetext{
${ }^{22}$ Más detalles en CAMUs, P. M. Ammien Marcellin, témoin des courants culturels et religieux à la fin du IVe siècle, pp.215-216.

23 Rosen, K. (1968). Studien zur Darstellungskunt und Glaubwürdigkeit des Ammianus Marcellinus. Mannheim : pp.164-165.

${ }^{24}$ Ver, por ejemplo, SANTOS, N. (en prensa). "Adivinación y magia en el Bajo Imperio: Amiano Marcelino y la legislación imperial" (en prensa).
} 
y fenómenos maravillosos pudieran explicarse científicamente no reduce por ello su valor indicativo ${ }^{25}$.

La lectura e interpretación de todos estos fenómenos religiosos puede llevarse a cabo de dos maneras diferentes, bien a nivel religioso bien a través de la explicación racional, sin que en ningún momento uno se manifieste excluyente con respecto al otro.

De esta manera, por ejemplo, la estela luminosa que Juliano contempla en junio del año 363 e interpreta como la estrella de Marte, que se hace visible a sus ojos bajo un aspecto siniestro, para el historiador de Antioquía no debe considerarse más que como un meteoro (Amm.Marc. 25.2.2).

Ahora bien, esta simple anécdota pone de relieve hasta qué punto la exégesis de estos fenómenos ambiguos constituye un paso intelectual y lógico por parte de los especialistas, quienes se apoyan para su interpretación en una tradición secular.

Entre dichos testimonios cabe destacar la atención escrupulosa que pone Amiano en el reflejo de las distintas manifestaciones de lo maravilloso, así como los motivos que aduce para mostrar cómo, en el caso de Juliano, las prácticas adivinatorias y de interpretación de los sueños pueden conciliarse perfectamente con el ejercicio de la razón filosófica (Amm.Marc. 21.1.7).

A través de todas estas manifestaciones de lo divino, entre las que se hallarían presagios, prodigios, oráculos, sueños, apariciones de seres divinos... ${ }^{26}$, lo único que hace el antioqueno es continuar con una tradición literaria asentada en Roma desde hacía varios siglos.

Resulta fácil comprobar, por otro lado, que los prototipos empleados por nuestro autor se hallan representados con cierta fluidez en otros escritores e historiadores latinos antiguos, como por ejemplo Virgilio, Tito Livio ${ }^{27}$, etc....

Junto a ello la terminología utilizada por Amiano para tales circunstancias (prodigium, miraculum, oraculum, portentum, omen...), a pesar de ciertas

25 MesLin, M. (1972). Le merveilleux comme langage politique chez Ammien Marcellin. Bruselas : p. 354.

26 MesLin, M. (op.cit., p.354) nos ofrece una lista de 78 casos de fenómenos maravillosos reseñados por nuestro autor.

${ }^{27}$ Su amplia colección de prodigia, reunidos en una obra por Julio Obsequente, conocería un gran auge durante todo el siglo IV. 
innovaciones, se halla muy próxima a la de los autores literarios que le precedieron.

Por consiguiente, mientras que, de manera tradicional, se venía haciendo una distinción entre las funciones del prodigio y las propias del presagio, en las Res Gestae amianeas, del mismo modo que podemos apreciar en el caso de los Escritores de la Historia Augusta ${ }^{28}$, el prodigio se nos muestra casi exclusivamente como una señal figurativa y determinante, sobre todo al considerarse como expresión última de un ordo fatalis (ver, por ejemplo, Amm.Marc. 23.5.4-8; 30.5.5 y 31.1.1ss.).

Como resultado de esta concepción (religiosa) del mundo el destino de los hombres que se revela en dichos signos se identifica perfectamente con el correspondiente tanto a Roma como a su Imperio.

En este contexto el emperador, a pesar de ser considerado como la figura más sobresaliente de la vida romana, se muestra incapaz de manipular tales presagios, que en numerosas ocasiones resultan de carácter ambiguo (ver, por ejemplo, Amm.Marc. 23.5.9), a excepción de casos muy especiales.

Sin embargo, ello no quiere decir que únicamente tengamos que ver en el desarrollo de estos hechos maravillosos una simple composición artificial de carácter literario y estilístico, cuyo objetivo no sería otro que el de dramatizar en cada momento el detalle descrito ${ }^{29}$.

Más bien este conjunto de señales, unido a la concordancia interna que nos presentan en todos los casos, así como la acrecentada gravedad de los presagios..., en el fondo nos esta indicando una intervención cada vez más apremiante de la voluntad divina en un momento clave en el que no sólo se halla en juego el destino de los hombres sino también el del propio Estado romano (Amm.Marc. 23.5.4).

Por ello, tanto en el caso de Valentiniano como en el de Valente, estas señales, muy claras y cada vez más próximas a la persona del emperador, sirven para notificar el desenlace fatal que el destino les tenía preparado a ambos desde mucho tiempo antes (Amm.Marc. 30.5.15-19 y 31.14.1ss.).

${ }^{28}$ En cuyas biografías de emperadores se reseñan 180 casos, cuyos prototipos remontan a Tito Livio, Suetonio, Virgilio y la tradición mística greco-latina.

${ }^{29}$ Más detalles, por ejemplo, en Richter, U. (1989). "Die Funktion der Digressionen im Werk Ammians". WJA 15, pp. 209ss. 
Así pues, en el fondo lo que nos están revelando todos estos prodigios celestes y sus correspondientes presagios son únicamente las decisiones del destino, que vienen marcadas por las alteraciones y vaivenes de la Fortuna (Amm.Marc. 15.5.1) $)^{30}$.

30 SANTOS, N. (2007). "Fortuna y fatum: la contingencia en el desarrollo de la historia según Amiano Marcelino". Cuadernos de Filología Clásica. Estudios Latinos 27, pp. 93ss. 